\title{
Applying the Adaptive Cycle Model to the Past, Present, and Future of SRM
}

\section{By Katie Santini, Kody Menghini, and John Malechek}

\section{Introduction}

Change is just as fundamental to human communities as it is to the plant and animal communities that we deal with daily on our rangelands. However, we humans do not like to confront our own change because it is often uncomfortable. We pay little attention to models of organizational change, but deal daily with models of plant community change, for example, states and transitions. In view of this disconnect, we were particularly challenged when Director Joel Brown proposed last August using the state-andtransition (S\&T) model to describe change within the SRM as the basis for the first Rangeland Cup competition.

We began our discussions in October by reviewing recent publications on states and transitions (particularly Briske and coworkers $\left.{ }^{1}\right)$ and recent $\left(\right.$ Brown $\left.^{2}\right)$ as well as early $\left(\right.$ Pehanec $\left.^{3}\right)$ papers on the status of SRM and the range profession in the public lands states of the West (Stoddart ${ }^{4}$ ). These papers strongly indicated that although there has been change in SRM and the range profession since the inception of SRM in 1948, there has not been the kind of radical change we would liken to a "state change" across some threshold into a new stable state as described by the S\&T model. ${ }^{1}$ Ironically, Stoddart and Pehanec were talking about many of the same things 40 years ago that SRM members are discussing today (eg, increasing urbanization of the American public, the place of livestock on public lands, is the SRM about cows and grass or the land, lack of recognition of the range profession, etc.). Rather than the S\&T model, we found the "Adaptive Cycle" described by Holling ${ }^{5}$ and elaborated by Holling and Gunderson ${ }^{6}$ to better describe our understanding of the various changes that have occurred in SRM and in the range profession and where they may be headed in the future.
One of the appeals of Holling's adaptive cycle model ${ }^{5}$ is that it takes into account functional change, whereas the S\&T model largely addresses structural change. Holling states that the adaptive cycle can provide a model of complex systems ranging from cells to ecosystems, societies, and cultures, and it can help us to understand how systems move and change. The adaptive cycle model incorporates concepts from population ecology to better describe the functionality of each of its 4 major stages. We illustrate this in Figure 1, using the sagebrush-bunchgrass ecosystem as an example (left panel) to demonstrate the model, and from that we apply the model to SRM and the range profession (right panel). We feel that the cycle provides a dynamic framework for assessing past and current phases of SRM and provides insight to potential futures of the organization.

\section{The Adaptive Cycle}

There are 4 stages of the adaptive cycle: reorganization $(\alpha)$, conservation $(K)$, release $(\Omega)$, and exploitation $(r)$. As a system moves through the 4 stages, potential and connectedness vary in strength. Potential can be thought of as "wealth" or factors that set limits for what is possible. In Holling's $\mathrm{s}^{5}$ words, it "...determines the number of alternative options for the future. Connectedness, or controllability, determines the degree to which a system can control its own destiny, as distinct from being caught by the whims of external variability." Importantly, the movement through the 4 stages is not uniform; short arrows on the figure-8 pathway suggest slow movement (perhaps over years or decades), whereas long arrows suggest very rapid change (Fig. 1). Readers must note that the above and following are highly abbreviated descriptions of this model and its implications. For a detailed treatment, see Holling ${ }^{5}$ and Holling and Gunderson. ${ }^{6}$ 


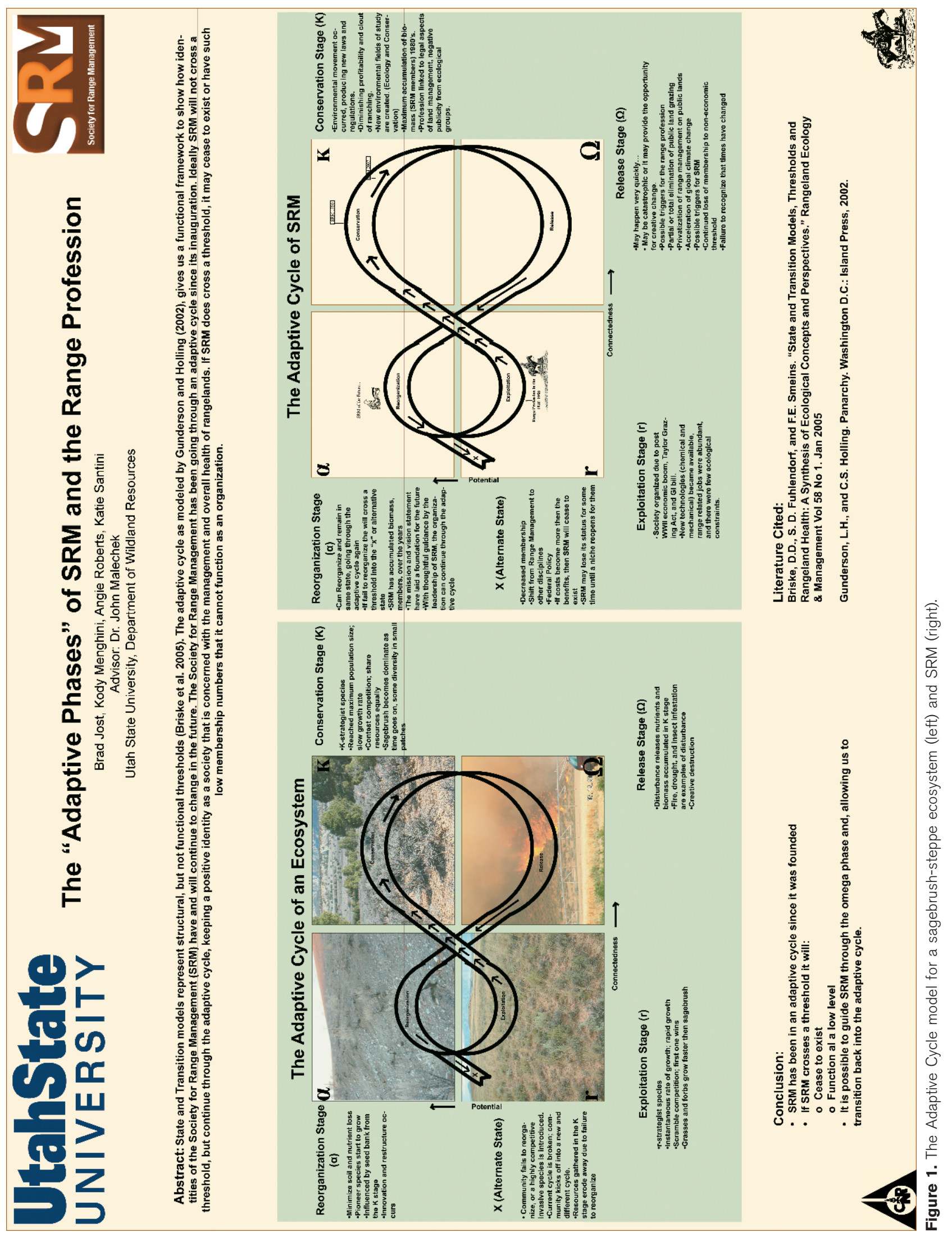




\section{An Ecological Example: Sagebrush-Steppe Ecosystem}

In a sagebrush-steppe ecosystem the adaptive cycle starts in the exploitation, or $r$, stage. Here, after a disturbance such as fire, pioneering species, characterized by short life spans, high reproductive rates, and fast population growth rates rapidly expand, filling the niches created and taking advantage of the resources available. Available resources might include soil nutrients, light, and water. Many of these pioneering species are grasses and forbs. In this stage there is relatively low connectedness and potential. Though the species are in competition for resources, they have not yet accumulated sufficient numbers or biomass to fully occupy all the space or resources (ie, there are still vacant niches). Over time, these species, as well as new immigrants, expand and continue to increase into the conservation $(K)$ stage.

In the $K$ stage, long-lived woody species such as sagebrush gain dominance of the ecosystem. Diversity-adding species, such as forbs and grasses, are represented in scattered patches throughout the system. $K$ species have long life spans, low population growth rates, and high resourceuse efficiency and are more specialized than are $r$ species. These species grow in abundance until they find the carrying capacity of a system and then level off. This stage may continue for long spans of time, provided that no major perturbation occurs. Accumulated biomass reaches a maximum level. Resources within the system become limited and must be shared among community members. This creates very high connectedness among all members in the system. Potential in the current system, as well as for future systems, is high. During this stage the seed bank that will be drawn upon by future generations is further augmented.

The release stage $(\Omega)$ of a sage-steppe community might be represented by a wildfire. Once the fire is started, it clears away woody biomass and releases nutrients accumulated during the $K$ stage. Potential is low during this brief stage because of all the unused nutrients and vulnerability of the site to external factors such as invasions, erosion, etc.

The last stage is the reorganization $(\alpha)$ stage. It is also a brief stage. Here, some new pioneer species may attempt to capture opportunity in order to utilize available nutrients, thereby increasing potential. The species that were previously dominant in the conservation stage are still represented in the seed bank, but are mingled with the new species, reducing the connectedness that previously existed. Through the recombination of these species, the new future is created.

As the community moves through reorganization into exploitation, there is risk of radical change. This is depicted as a kick-out point $(\mathrm{X})$. If a system fails to reorganize because of intrusion of some external factor(s), such as invasion and domination by the nonnative species cheatgrass (Bromus tectorum), the system may kick out into an alternate state, ie, it would cross a threshold into a new and undesirable stable state, in the words of S\&T theory.

\section{The Adaptive Cycle: SRM Model}

The Society for Range Management was born in 1948, its $r$ stage. The founders of SRM saw an open niche not being filled by other organizations such as the Society of American Foresters, the Ecological Society, etc. ${ }^{3}$, and range scientists, range managers, and practitioners rapidly filled it. Several national and world events interacted to promote rapid growth of both the range profession and SRM. These included the post-World War II economic boom stimulating the livestock industry, the GI Bill providing the means for large numbers of veterans to attend college with many majoring in range management, and the enactment of the Taylor Grazing Act creating a demand for range managers in the Forest Service and Bureau of Land Management. The advancement of new technologies such as herbicides (2,4-D and 2,4,5-T) and mechanical treatments (chaining and rangeland seeding) also created job opportunities for range managers and increased activity in other range-related fields such as ranching. With relatively few environmental constraints and policies on these practices, large-scale land manipulations proceeded rapidly, and SRM continued to grow and fill its niche in the $r$-stage until the late 1960s and early 1970s.

As the country moved into the 1970 s, we saw the birth of the environmental movement with the enactment of many new laws and regulatory policies. These included the Endangered Species Act, the National Environmental Policy Act, the Clean Water Act, and the Clean Air Act. These regulations substantially reduced the public land management agencies' involvement in large-scale range improvement projects, especially those done for the purpose of increasing forage for livestock.

This period also witnessed an increase in the number of "environmental" degrees offered by universities, thereby diverting at least some students who may have otherwise majored in range management. Job slots for young, upcoming range managers were also on the decline because most of the available positions had been filled by post-World War II graduates. Also, during this time, several new natural resource professional organizations emerged, offering alternate professional affiliations for professionals.

All of these events caused SRM to enter the $K$ (conservation) stage where both potential (wealth, in a broad sense) and connectedness (controllability, linkages to other "competitors" and to the environment) are at their maxima. Membership peaked in 1980 and was followed by a decline until the recent past.

We believe that the SRM is still somewhere in the $K$ stage today. Recall that movement from stage $r$ to $K$ can take a very long time. Some may argue that SRM has already reached its "carrying capacity" in its present form. Biomass (membership, finances) is high, but there are still high amounts of potential (influence) and connectedness (ties to other organizations, range uses, and values) to be gained. 
The next stage that SRM may enter somewhere in the indefinite future is the release stage $(\Omega)$. Should a release occur (the model predicts that this stage is relatively brief), it would create a change that might be either catastrophic or beneficial, depending on how it is handled. Possible triggers of undesirable change might include a continued loss of membership to the point of financial insolvency, the removal of livestock grazing on public lands, creation of more environmental and legal constraints, or a failure to recognize that times have changed ( Pehanec $^{3}$ was lamenting this latter point 40 years ago). On the other hand, the change can be highly beneficial if it is brought about by foresight and creative leadership.

After a release $(\Omega)$, reorganization $(\alpha)$ might, and ideally would, occur. This is where SRM could reorganize in a major way to continue through the adaptive cycle and into the exploitation stage again. Reorganization might take the organization into a whole new future, building upon the knowledge, financial, and influence capital now in its metaphorical seed bank, while minimizing its soil (goodwill of its members) and nutrient (finances) loss. However, if these nutrients, biomass, and biodiversity that were accumulated in the conservation stage are eroded away, then SRM might cross a major threshold to enter the $\mathrm{X}$ stage (alternative state) and begin an entirely new and unknown adaptive cycle. Or it might simply cease to exist.

\section{Discussion}

There are multiple indications that SRM is changing and is continuing to build upon its influence and service to membership, but, for the most part, it is still residing in the conservation stage. The mission statement and vision of SRM include laudable concepts of continuing education, collaboration, sustainability, societal values, and balance. Publications in Rangeland Ecology \& Management reflect a diverse variety of topics, not just those dealing with historic range topics of cows and grass. The Reno meeting was entitled "Traditions and Transitions," reflecting both the legacy and future of the profession. The Reno meeting's logo was an outline of the trail boss with recreationists, livestock, wildlife, water, and managers in it. Membership demographics are changing also, especially with regard to the growing (but still too small) number of women professionals.

Our research on this topic leads us to believe that although positive change is under way, it is not occurring at the same rate and with uniform enthusiasm throughout the organization. The Board of Directors is obviously confronting the need for change, as indicated by the article by Director Joel Brown in the August 2006 issue of Rangeland Nerws. (This article apparently sparked the Rangeland Cup competition topic.) It might even be argued that they are moving into the beginnings of the release and reorganization stages. However, many SRM members have not made this move and are still deep in the conservation stage.

What is the nature of this disconnect? Turning again to an analogy from ecology, Briske and coworkers ${ }^{1}$ state the following: "Structural and functional thresholds are interrelated to varying degrees, but functional thresholds are anticipated to lag behind structural thresholds based on the time required to modify ecosystem processes." Most of the structural components of SRM (leadership group, national office, sections, committees, etc.) have been in place for many years, but a new and important component (a "structural threshold"?) was implemented in February 2002, with the adoption of the Strategic Plan for the Society for Range Management. This plan outlines everything that we believe needs to be done in order for SRM to continue as a great organization. However, we sense that the membership, in general, has not signed on. What is our basis for this statement? Although we had been researching this topic since October of 2006, working with knowledgeable people involved in range management and SRM, we had not heard about this plan until late January when we stumbled upon it and found it very similar to what, by then, we thought SRM should do. The fact that we had worked with several SRM members (consisting of past board members, past presidents, and current committee members) and had never heard of this plan indicates that there is a major lack of communication about and commitment to what we feel is a very sound plan for the future of a vital and relevant organization. Lag time between structural and functional change is natural, but can hamper SRM from becoming the organization it deserves and needs to be. SRM must address this lag and start functioning in the reorganization state, preparing for the next exploitation state. Being proactive and having predetermined actions to accomplish the mission and vision of SRM can reduce the distance between structural and functional change in SRM.

In conclusion, we believe that the adaptive cycle model accurately describes the history of SRM and, importantly, provides some insights into at least 2 possible futures. The desirable one of these-constructive, proactive change through the release and reorganization stages - can be achieved by energetically implementing the strategic plan that is already in place. This will require improved communication throughout SRM and building of commitment and enthusiasm within the membership at large.

\section{Acknowledgments}

We especially thank Ben Baldwin and Angela Roberts, Department of Wildland Resources, Utah State University, for their valuable suggestions and criticism throughout the development of this project.

\section{References}

1. Briske, D. D., S. D. Fuhlendorf, and F. E. Smeins. 2005. State and transition models, thresholds and rangeland health: a synthesis of ecological concepts and perspectives. Rangeland Ecology \& Management 58:1-10.

2. BRown, J. R. August 2006. The future...what's that?? Rangeland News:1-2. 
3. Pehanec, J. F. 1967. The Range Society is at the crossroads. Journal of Range Management 20:125-128.

4. Stoddart, L. A. 1965. What hope for grazing on the public lands? Journal of Range Management 18:109-112.

5. Holling, C. S. 2001. Understanding the complexity of economic, ecological, and social systems. Ecosystems 4:390-405

6. Holling, C. S., And L. H. Gunderson. 2002. Resilience and adaptive cycles. In: L. H. Gunderson and C. S. Holling [eds.]. Panarchy. Washington, DC: Island Press. p 25-62.
Authors are Undergraduate Students (Santini and Menghini) and Professor and Rangeland Cup project advisor (Malechek), Department of Wildland Resources, Utah State University, Logan, UT 84322-5230, malechek@cc.usu.edu.

(Editor's Note: This is a short narrative of the winning poster of the Rangeland Cup competition.) 


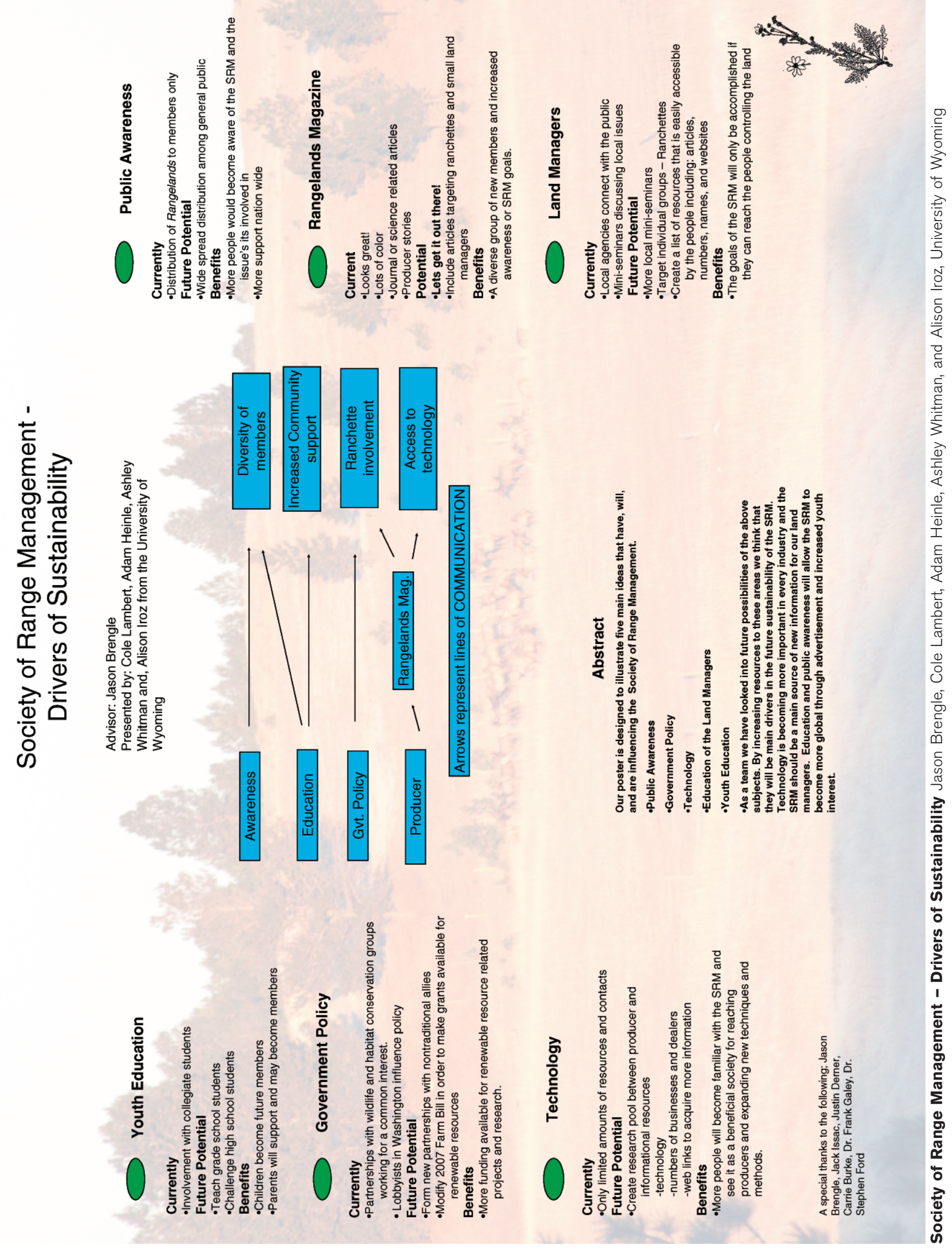




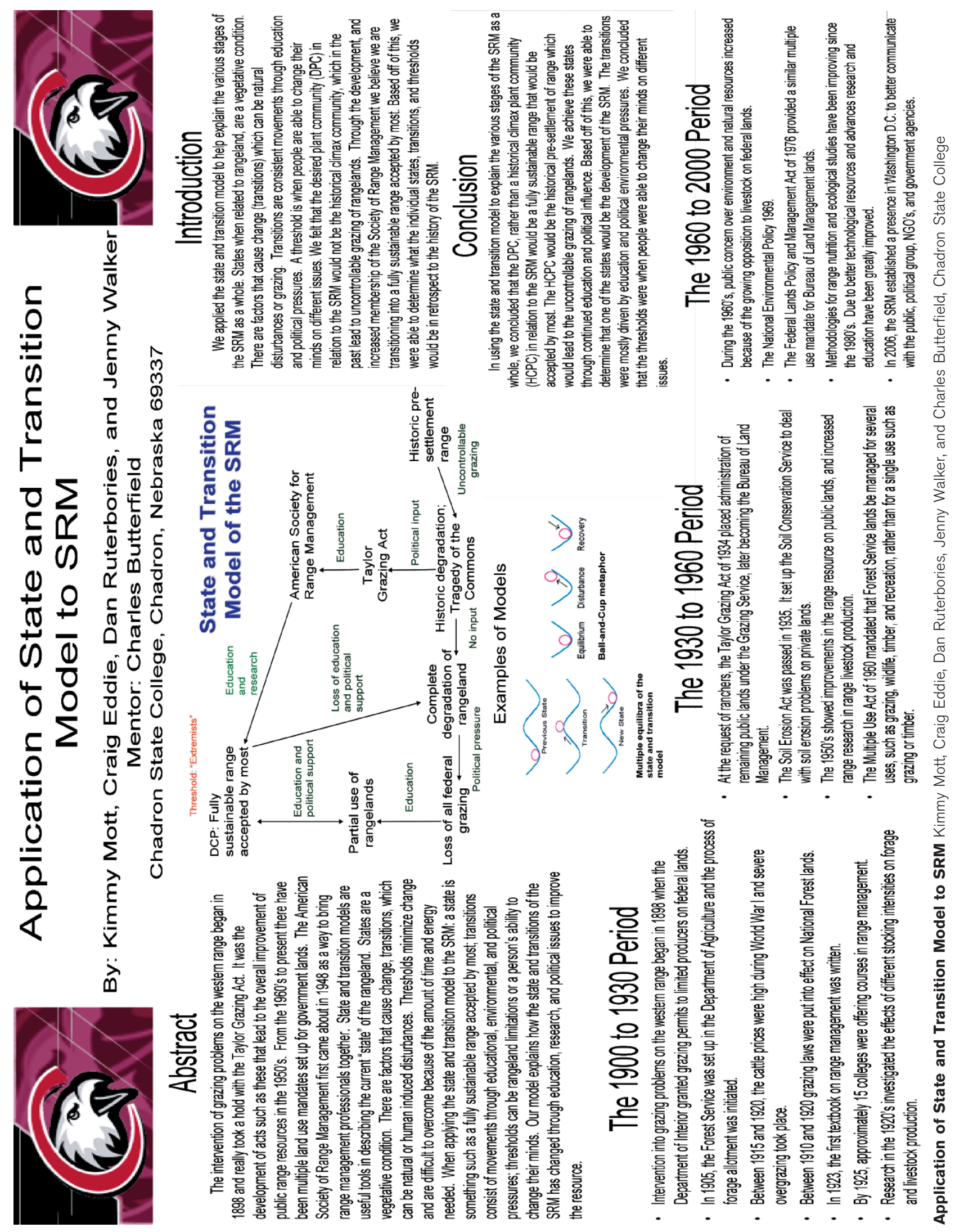




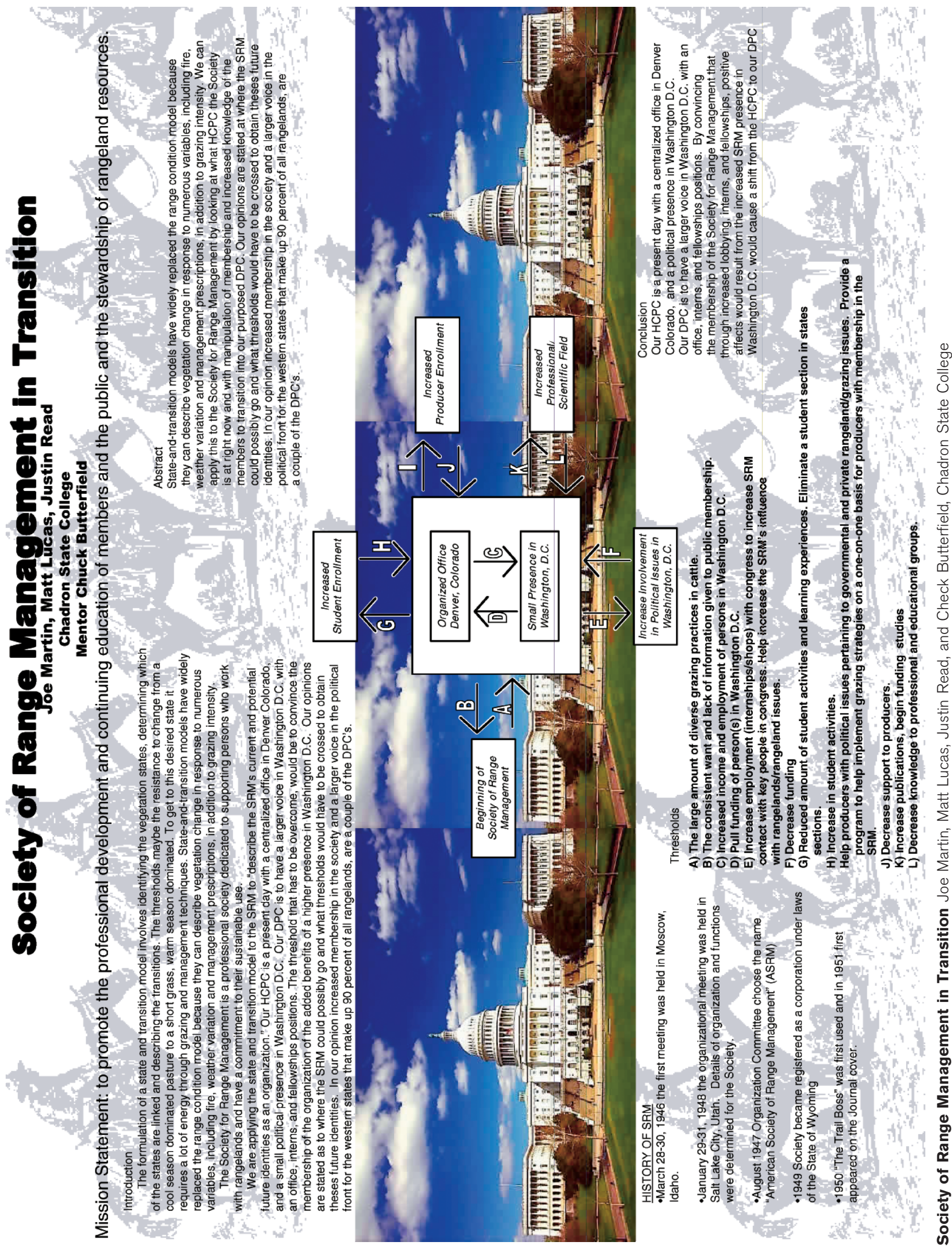



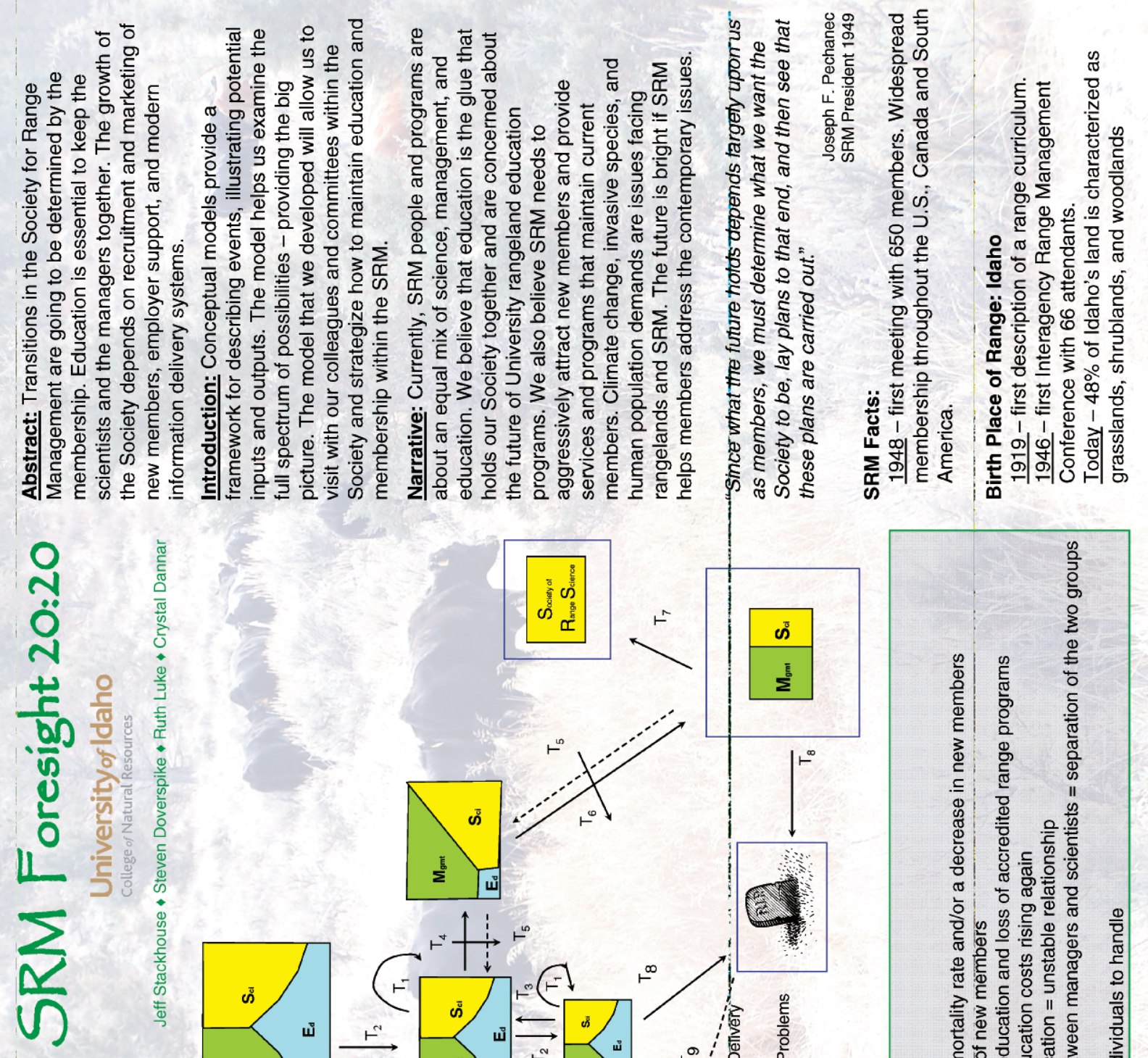

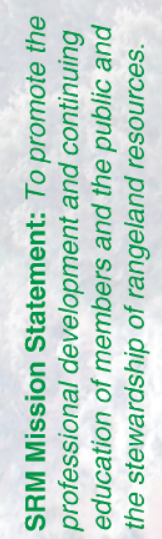
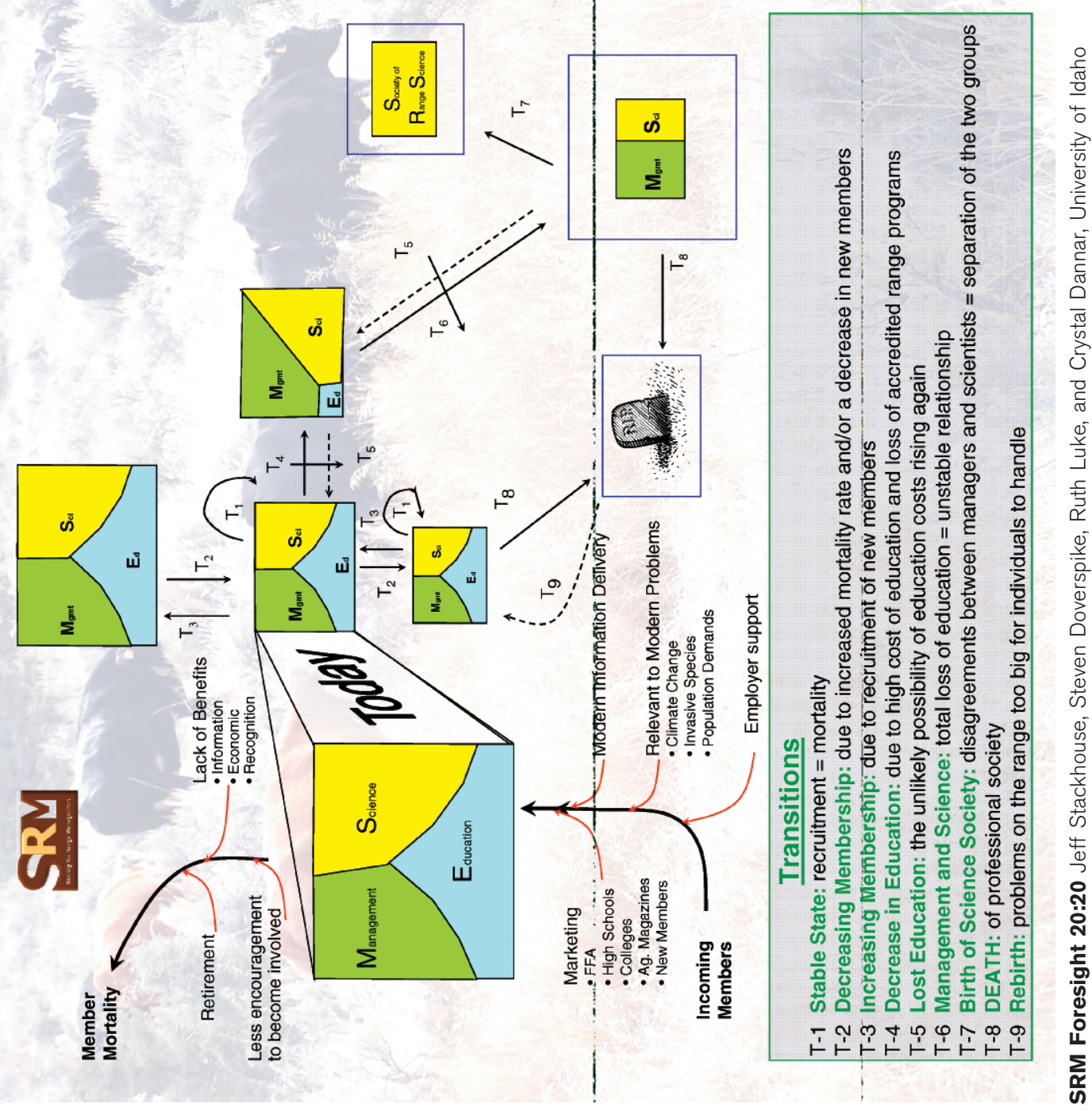


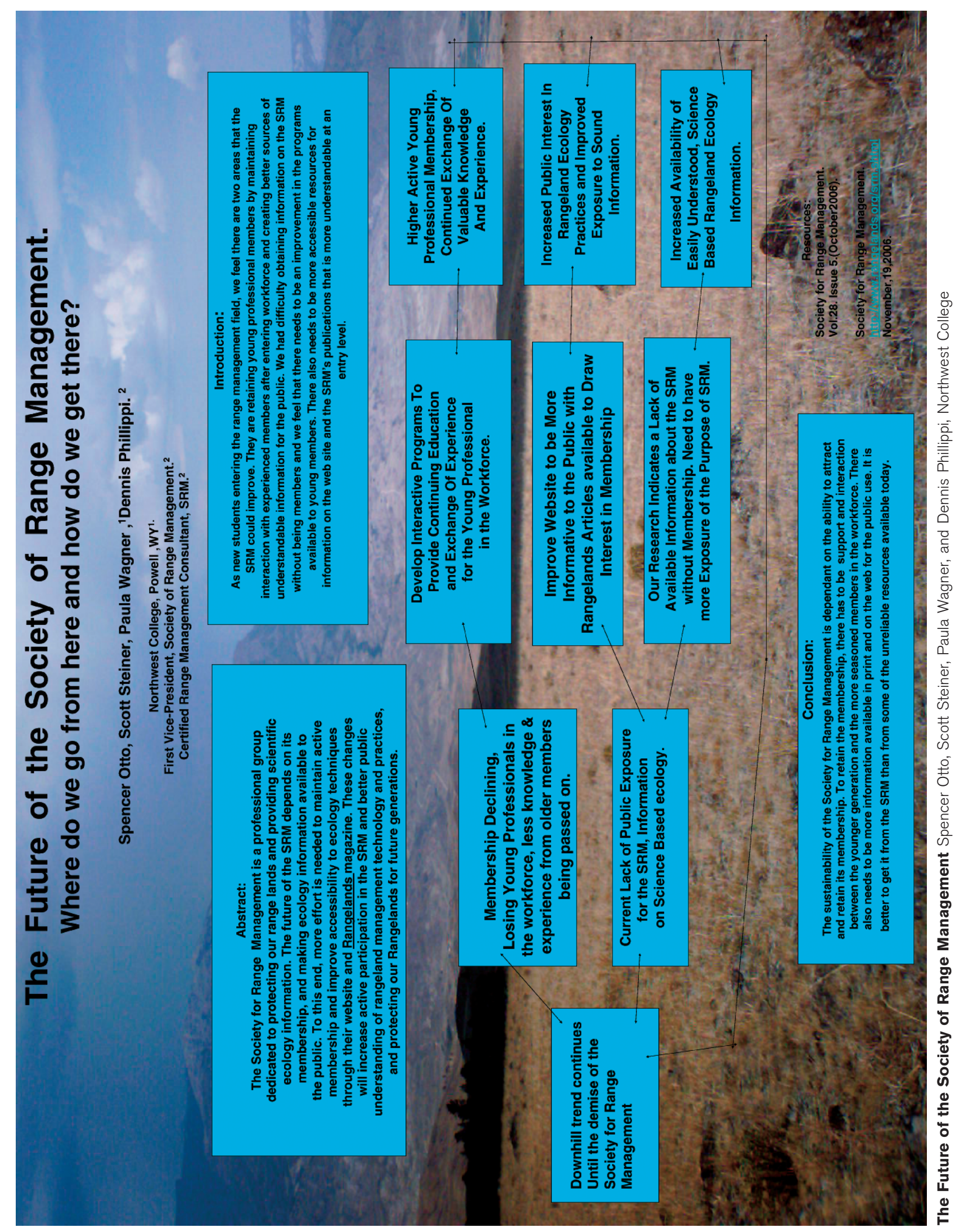




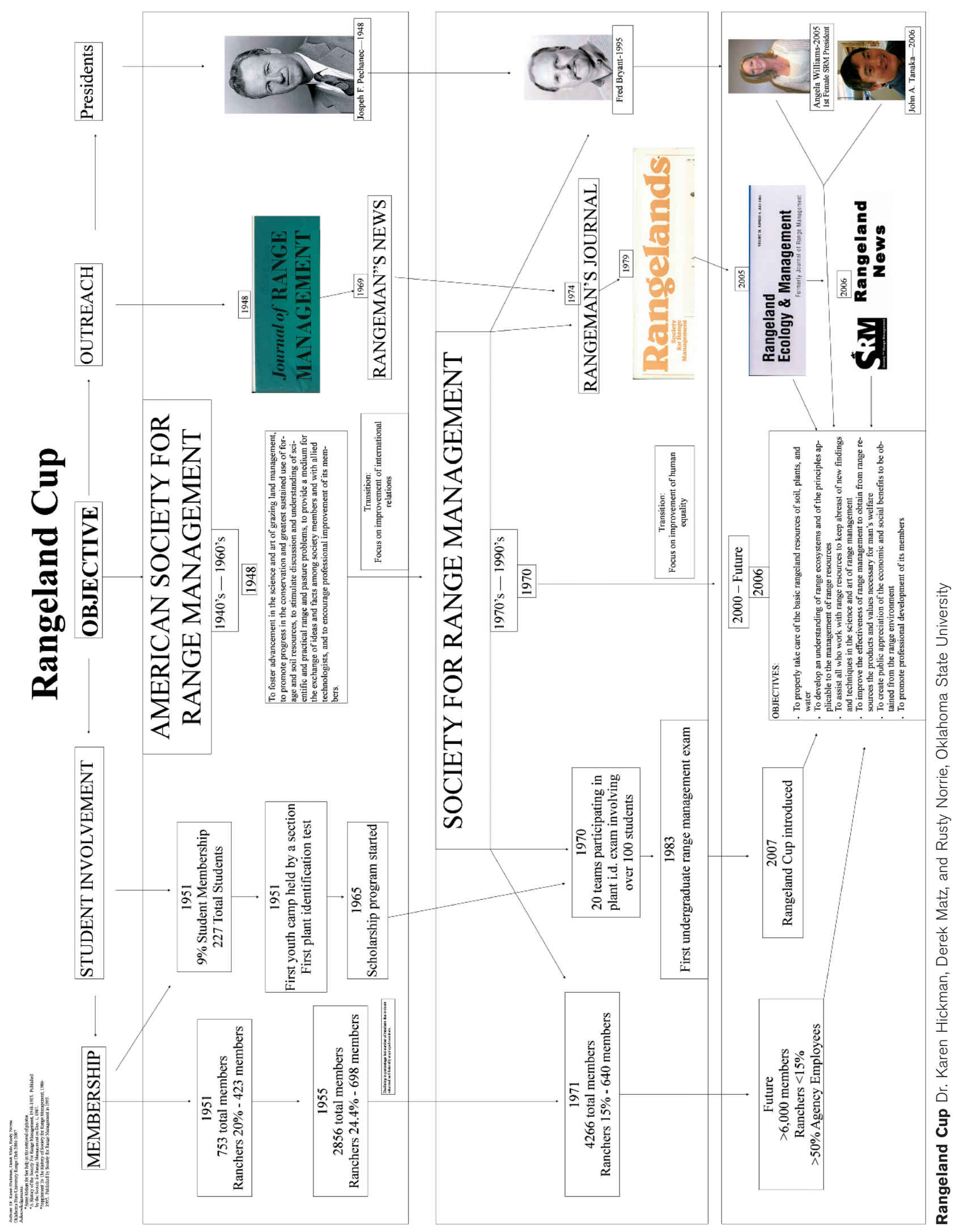




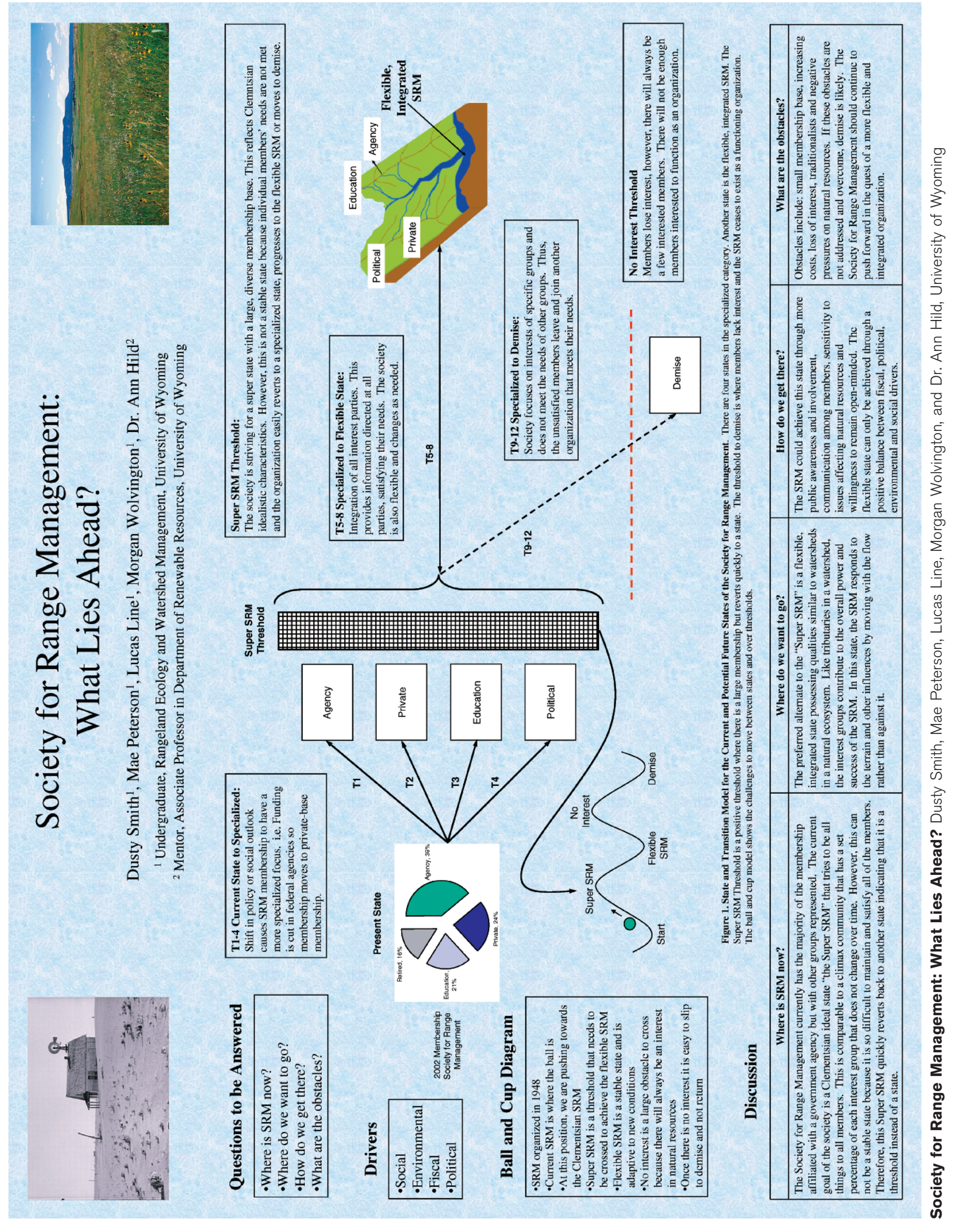

